\title{
How to enhance sustainable chemistry in a non-technological way?
}

\author{
G. L. L. Reniers ${ }^{1,2} \&$ K. Sörensen ${ }^{1}$ \\ ${ }^{1}$ Faculty of Applied Economic Sciences, Research Groups ARGoSS and \\ ANT/OR, University of Antwerp, Belgium \\ ${ }^{2}$ Centre for Economics and Corporate Sustainability (CEDON), Belgium
}

\begin{abstract}
To achieve sustainable industrial chemical processes and products, companies, research centers and academia tend to focus mainly on technological solutions such as cleantech, green technology, process intensification, new catalysts, new membranes, ecofining, etc. However, non-technological approaches are essential as well to succeed in adequate sustainable chemistry. Cluster management, sustainable supply chain management, chemical leasing, integrated management systems and business models, societal expectations, etc. are all important nontechnological aspects of sustainable chemistry. To date, most of the know-how and expertise on non-technological issues is developed on an individual company or academia basis and in a fragmented way. It is nonetheless crucial for the vision of sustainable chemistry to be realized that not only novel technology is conceptualized and developed by individual initiatives, but also that innovative management models, intra-organization models, and inter-organization models are elaborated, promoted and implemented by academia and by industry on a much broader scale.
\end{abstract}

Keywords: non-technological sustainable chemistry, chemical leasing, integrated management systems.

\section{Introduction}

According to the definition of Brundtland, sustainable development is the development that fulfils the needs of the present generation without compromising the ability of future generations to meet their own needs [1]. This means that long-term thinking and acting is needed. As the advantages of a long- 
term approach are not always directly recognized as profitable on the short-term, it is essential that a constant overview of the value chain is installed in a company and that the opportunities that can be found in such a long-term approach are recognized. Value chain opportunities such as chemical leasing, organized supply chains and transport, waste exchange, cradle-to-cradle actions, integrated SHESQ management systems or strategic collaboration may be elaborated within organizations to anchor sustainability as a vision.

Managers are discovering that the indicators that gauge sustainability can also be indicators of efficacy - that is, how well a company is run. From the management of corporate liabilities to new market ventures, a sustainable business strategy can improve all segments of corporate activity. It can be argued that management with focus on sustainability is a good proxy for gauging overall management capabilities at strategic, tactic and operational levels.

Traditionally, sustainability issues such as environmental efforts and social welfare expenditures have been viewed as costs that correlate negative with returns. However, studies suggest that there are several opportunities for competitive advantage and increased profits to be gained by strategic sustainability initiatives [2].

This reasoning reflects a shift from viewing business expenditures in a static world, to viewing them in a dynamic one based on innovation. Porter and Van der Linde [3] argue that in static model, firms and clusters of firms have already made their cost-minimizing choices and therefore any imperative to spend 'in the name of sustainability' inevitably raises costs. Such a static world falsely assumes that profit-seeking in se leads automatically to the pursuit of all profitable innovations. However, a dynamic world, which is actually the real world that companies operate in, is shaped by the stimulation and development of innovations. In other words, managing with focus on sustainability, that is, enhancing sustainability in a non-technological way, have helped spark (nontechnological as well as technological) innovations that have eventually improved chemical process efficiencies, tapped new markets, streamlined productions and materials use, reduced pollution, and led to many other benefits.

Nonetheless, public and private researchers still need to bestow much greater effort in studying essential non-technological domains for improving sustainability in the chemical industry and achieving sustainable chemical products and processes. This paper deals with the different fields of nontechnological research deserving more attention by academia and industry.

If supply chain management is aimed at installing beneficial partnerships and seamless linkages between multiple parties operating at different levels of the supply chain to avoid unnecessary logistics costs, it is referred to as vertical logistics collaboration. Apart from the well-established concept of vertical collaboration, horizontal collaboration can be distinguished. Horizontal collaboration is used to refer to concerted practices to "share private information, facilities or resources to reduce costs or improve service between companies (competing or unrelated) operating at the same level(s) in the market" [4]. 
It is obvious that a chemical enterprise has several possible ways of installing organizational improvements for its aim to optimize chemical process or product sustainability. Figure 1 displays the different perspectives.

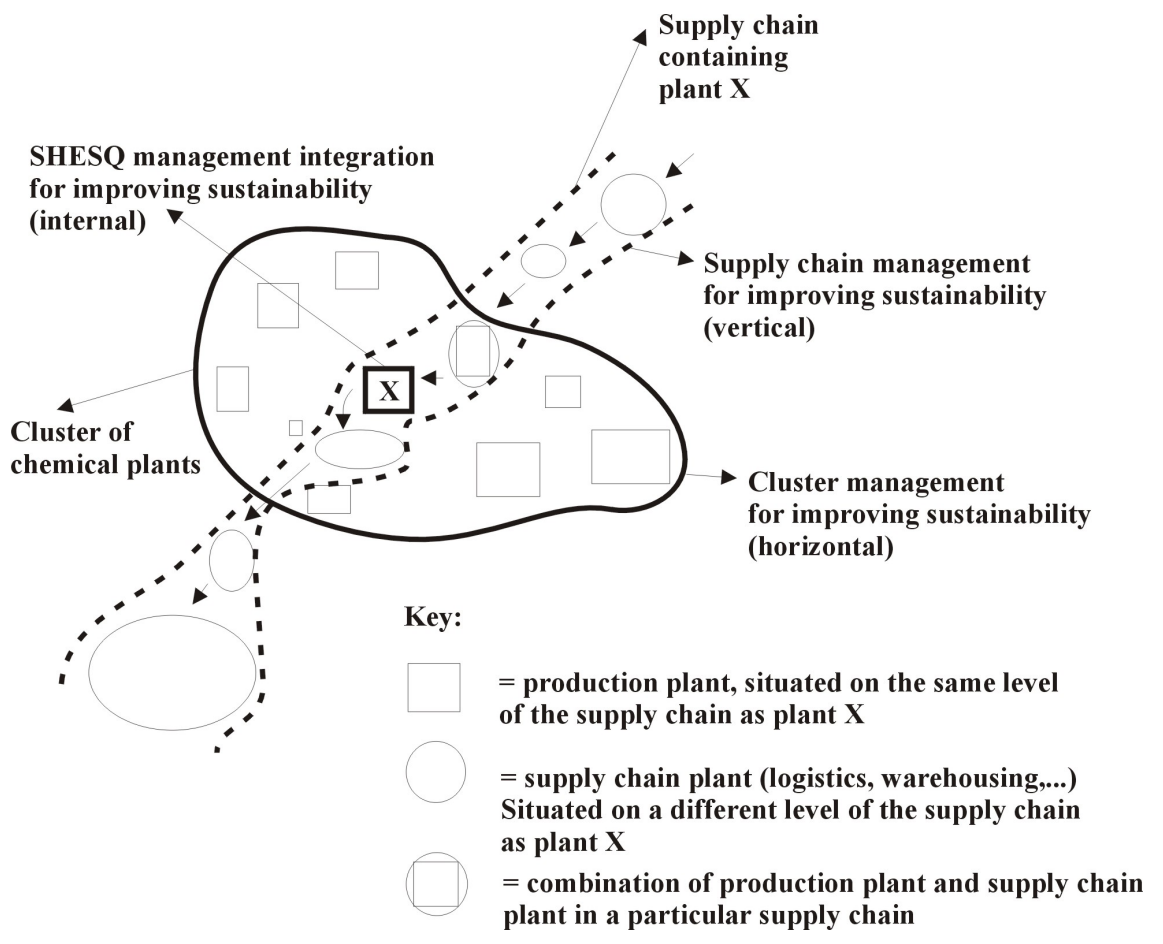

Figure 1: Different perspectives for achieving sustainable chemistry in a nontechnological way.

As a first (horizontal) perspective, cross-plant management between corporations situated on the same level of the supply chain can be mentioned. This innovative perspective for enhancing sustainability in a non-technological way is called multi-plant management or cluster management.

As a second (vertical) perspective, supply chain management is envisioned. A supply chain policy trying to optimize sustainability within a chemical industrial area is aimed at realizing a more efficient chemical logistics chain.

The third (plant-internal) perspective is concerned with a company's safety, health, environment, security and quality management systems. By integrating these aforementioned management systems, chemical processes and products may be efficiently approached from a holistic people, planet and profit viewpoint.

The transition from a 'traditional' chemical plant towards a truly 'sustainable' corporation may only be achieved through the use of adequate business models directed at cooperation and multi-plant management. The three (nontechnological) perspectives for elaborating these business models and leading 
towards the 'sustainable company' vision are discussed more in depth in the following Sections.

\section{Cluster management}

Although collaborative arrangements within many industries are well-known and often successful and appreciated, further optimization of these arrangements is many times possible. By augmenting collaborative agreements and relationships and by linking up with other firms on the same level of the market, a company may enjoy options otherwise unavailable to it, such as better access to markets, pooling or swapping of technologies and production volumes, access to specialized competencies, lower risk of R\&D, enjoying larger economies of scale, benefiting from economies of scope, etc. [5, 6]. This way, collaborative arrangements often lead to more sustainable solutions and situations. For example, Seuring and Müller [7] discuss the cross-integration of integrated chain management and supply chain management from a conceptual viewpoint and describe five case-studies proving that collaborative arrangements are the only way to improve the competitiveness of the supply chain while reducing environmental burden.

The development of industrial eco-parks or industrial ecology is another example of how companies may improve their sustainable behavior through collaboration. Sterr and Ott [8] indicate that larger regional industrial areas may be more suitable for creating sustainable industrial ecosystems. At the same time, these authors also point out that the larger the industrial region, the more difficult to establish the necessary trust and coordination among the actors for setting up successful collaborative agreements.

To build stronger and more sustainability-oriented organizations, Lozano [9] suggests employing the Japanese concept of Kyosei, or "spirit of collaboration", complemented with a Multi-dimensional Sustainability Influence Change memework called MuSIC. This memework rightfully states that, in order to create an (ideal) efficient and effective paradigm shift towards sustainability within an organization, this change process should simultaneously happen in several dimensions, from individuals, groups and the organization through alignment and support by leadership and institutional frameworks, to the congruent change in informational, emotional and behavioural attitudes [9]. However, MuSIC does not include the inter-organizational dimension. Nonetheless, it is this very important inter-organizational dimension where a paradigm change process is needed for initiating collaboration between companies, which leads to truly sustainable industrial clusters. In our opinion, MuSIC should therefore be expanded with a cross-organizational dimension, providing a guide to understanding not only the intra-organizational interactions, but also the inter-organizational interactions, and helping support an organisation's as well as an industrial park's sustainability transformation.

A framework for allowing and enabling companies to take joint strategic decisions (e.g. investments) should be shaped, based on a multi-plant or cluster 
vision. Multi-plant opportunities with respect to innovativeness and sustainability should be identified and mapped.

An innovative cluster-leveled policy and the resulting innovative policies on individual companies' levels should lead to strategic decisions being implemented on tactic and operational levels, aiming to make chemical products and processes more sustainable.

Cluster management may also lead to the transition of managing safety, health, environment, security and quality within a group of chemical plants. By taking people (safety and security), planet (environment) and profit (quality) simultaneously into account in a cross-plant SHESQ management system/concept, improvement steps for individual plants may be achieved. Ethical aspects may also be introduced into this cross-plant management system and, by extension, to the individual plants. This way, a chemical industrial area may increase its efficiency, as well as greatly improve its internal and external multi-corporate image. Such an approach may also lead to an important competitive advantage for the individual companies participating into the cluster initiative.

\section{Supply chain management}

Another crucial factor in the development of sustainable chemistry is managing logistic processes within and between (chemical) companies in an optimal way. Obviously, technical innovations, such as process and product improvement and the replacement of fossil fuels with renewable raw materials, can deliver an important contribution to sustainability. However, the benefits of these innovations can be easily undone by an inefficient organization of the supply chain, both within a company and between different companies. To put it bluntly, a production process improvement that reduces $\mathrm{CO}_{2}$ emissions by $20 \%$ can easily be undone if twice as many kilometers must be completed to deliver this product to the customers. Notwithstanding the evidence of logistic optimization, examples of major inefficiencies in the organization of logistics processes between companies (for example, large quantities of identical products are transported in both directions between chemical clusters) or within firms (e.g., large stocks resulting from a lack of demand forecasting) are all too common.

Logistics and supply chain management are not equivalent to physical distribution, but also include the sound management of the information necessary for an effective control of the supply chain. Where performance measures of supply chains in the past have been predominantly cost-based, a broad consensus has formed in the post-Kyoto period that logistics operations should proceed in a more sustainable way [10-12].Consequently, the optimization of the various components of the supply chain increasingly take into account criteria related to sustainability and the environment [13]. Simultaneously, various social criteria, such as working time restrictions, are also taken into account.

Sustainable optimization of the supply chain adds an additional level of complexity. Software for vehicle routing, scheduling and planning of the supply 
chain is therefore still based solely on cost. One reason is the lack of an overall methodology for making decisions involving multiple objectives simultaneously. Cost and sustainability are however both important, but conflicting criteria are present and a trade-off must be made between them.

Logistics in the chemical industry also differs significantly from logistics in other sectors and therefore requires a specific approach. This has an impact on many aspects of the supply chain such as inventory management, production management and distribution management. In the chemical industry transported products are often hazardous, which imposes important restrictions (permits, regulations) on the organization of the supply chain and possibly affects its flexibility. Another difference is that chemicals, unlike most other types of freight, can be transported by pipeline. This transport mode has some very specific properties, such as a lack of flexibility on the one hand, but a very small variable cost on the other hand. The fact that often large quantities of homogeneous products have to be carried makes the chemical industry an important subject for a clearing system. In such a system a competing supplier can perform the physical production and delivery of a generic product to a customer clients if this is advantageous (for example, because the competitor is located much closer to the customer). The competitor will then invoice the supplier for the services provided, or perform similar services and incur similar costs. In such a system, a supplier of ammonia in Houston can leave it to an Antwerp-based supplier to deliver to its customers in Antwerp and vice versa. In this way, unnecessary transportation and logistics operations are avoided. Evidently the success of such a system requires a high degree of openness between the various chemical companies.

\section{SHESQ management integration}

Operational risks may be classified into four distinct management domains: safety and health, security, environment, and quality. Management systems and norms are available to organizations in each of the four domains (e.g. ISO 9001:2000 (quality), OSHAS 18001:2007 (safety and health) en EMAS2, ISO 14000:2004 (environment)). The traditional approach of employing a different management system in every domain for dealing with operational risks in a company has resulted in parallel, and thus entirely separate, management systems. Every domain has its own history, specificities, and insights, such as company know-how (quality), expectations from the Government and other stakeholders (safety and environment), and societal evolutions (security). As such, it can be understood and explained that separate obligations, models and instruments have emerged in the different domains: domain-specific legislation, management models, risk analysis techniques, education and training sessions, distinct functions within companies (such as e.g. the prevention advisor, the environmental coordinator, the security liaison officer), etc. For every management domain, different performance indicators are used as well.

Nevertheless, public as well as private bodies recognize the need for an integrative approach to deal with the four domains, besides a specialist approach, 
and framed within the sustainability concept of organizations. Karapetrovic and Jonker [14] indicate that integrating standardized management systems leads to synergetic effects and significant savings in business operations. According to Smith [15], an integrated management system has the additional advantage that improvements are implemented simultaneously within all four domains. This way, an integrated management system works in a pro-active manner. Embedding sustainability concepts into the system results in a continuous improvement in all business operations (e.g. also in case of technological innovations or in case of supply chain optimizations).

The evolutionary process of a mono-disciplinary risk approach towards an integrative risk approach within organizations can be illustrated via the development of Corporate Social Responsibility, which is a non-technological business concept.

\section{Conclusions}

The objective of writing an article from a managerial viewpoint consists in leveraging the search for truly sustainable chemical products and processes, and to disseminate the non-technological ideas and concepts to captains of industry and to leaders of the public sector, as well as to company management (within all organizational levels and from all different departments and disciplines).

It is obvious that realizing sustainable chemistry strongly depends on the levels at which innovative technological breakthroughs are possible and develop. This article indicates that inter-organizational cluster policies, managing the chemical supply chain more efficiently and integrating SHESQ management systems within companies, should also be considered as essential nontechnological ways to stimulate innovation and sustainable technology.

Adequate cross-company policies for example lead to more effective safety and security within industrial parks, as well as increased energy-efficiencies and less waste streams. Optimizing the chemical supply chain leads amongst others to economic and ecological more efficient product streams. Integrating management systems results e.g. in continuous improvement of the sustainable chemistry concept within corporations, leading to competitive advantages.

\section{References}

[1] United Nations (1987). Report of the World Commission on Environment and Development. General Assembly Resolution 42/187, 11 December 1987.

[2] Reinhardt, F.L. (1999). Bringing the environment down to Earth, Harvard Business Review, p. 149-157.

[3] Porter, M.E., van der Linde, C. (1995). Toward a new conception of the environment - Competitiveness Relationship, Journal of Economic Perspectives, 9(4), p. 97-118. 
[4] European Union (2001). Guidelines on the applicability of Article 81 of the EC Treaty to horizontal collaboration agreements, European Commission Notice 2001/C 3/02.

[5] De Man, A., van der Zee, H., Geurts, D., Kuijt, M., Vincent, N. (2000). Competing for partners, Pearson Education, Zeist, The Netherlands, 211p.

[6] Contractor, F.J., Lorange, P. (2002). Cooperative Strategies in international business. Joint ventures and technology partnerships between firms. Pergamon, Amsterdam, The Netherlands.

[7] Seuring, S., Müller, M. (2008). From a literature review to a conceptual framework for sustainable supply chain management, Journal of Cleaner Production, 16, pp. 1699-1710.

[8] Sterr, T., Ott, T. (2004). The industrial region as a promising unit for ecoindustrial development - reflections, practical experience and establishment of innovative instruments to support industrial ecology, Journal of Cleaner Production, 12, pp. 947-965.

[9] Lozano, R. (2008). Developing collaborative and sustainable organizations, Journal of Cleaner Production, 16, pp. 499-509.

[10] European Commission (2007). Freight transport logistics action plan. Communication of the Commission of the European Communities.

[11] Lambert, D.M., Cooper, M.C. (2000). Issues in supply chain management. Industrial Marketing Management, 29, p. 65-83.

[12] Lamming, R., Hampson J. (1996). The environment as a supply chain management issue. British Journal of Management, 7, S45-S62, 336.

[13] Christopher, M. (1999). Logistics and supply chain management: Strategies for reducing cost and improving service $\left(2^{\text {nd }}\right.$ Ed.), International Journal of Logistics Research and Applications, 2, 103.

[14] Karapetrovic, S., Jonker, J. (2003). Integration of standardized management systems: searching for a recipe and ingredients. Total Quality Management, 14(4), p. 451-459.

[15] Smith, D. (2002). IMS: The Framework, London: British Standards Institute. 